\title{
EXPLORANDO EL LADO OCULTO DE LOS RESULTADOS ELECTORALES DE 1994 EN EL SALVADOR
}

\author{
Mario Lungo*
}

1

A partir de la conversión del FMLN en partido político legal - Imente reconocido en 1993, y ante las elecciones que se celebrarían en marzo de 1994, se generó un amplio espectro de opiniones y espectativas en torno a su papel en este proceso, los resultados que podría obtener y, en general, sobre su papel en el proceso de construcción de la democracia en el país. Explicable por muchas razones, en las opiniones prevaleció el énfasis coyuntural y en las espectativas predominaron los deseos sobre el análisis objetivo.

Las elecciones se desarrollaron en dos vueltas y sus resultados han sido ampliamente difundidos. Sin embargo, y esto es importante para el futuro del país en general y del FMLN en particular, es necesario analizar los factores que permanecen oscuros, los procesos que configuran el lado oculto de los resultados electorales y que, por responder a tendencias estructurales de mediano y largo plazo, quedan involuntariamente de lado en la mayoría de los análisis hechos.

* Catedrático del Departamento de Arquitectura de la UCA

Ponencia presentada en el Latin American Center de la Universidad de California/Los Angeles/Junio de 1994. 
Estas notas tratan de contribuir a esta impostergable tarea, planteando, con carácter preliminar e hipotético en algunos momentos del análisis, cuales son algunas de estas tendencias estructurales que complementarían los análisis coyunturales mayoritariamente realizados hasta el momento.

2.

omo es obvio, los primeros análisis sobre el evento electoral se dedicaron a los porcentajes obtenidos por los distintos partidos y su comportamiento respecto a pasadas elecciones; en un segundo momento se comenzó a observar estos resultados en relación a las distintas áreas geográficas (municipios y departamentos en este caso), cuestión de singular interés en el país pues se suponía que el FMLN ganaría con facilidad en las zonas en que esta organización ejerció un fuerte control político-militar durante los años del conflicto.

Lo anterior, aunque de indudable importancia, no es suficiente. Es necesario hacer un estudio del comportamiento electoral de cada uno de los sectores que conforman la sociedad salvadoreña, especialmente porque las elecciones de 1994 constituyen las primeras realmente libres y plurales desde los años 20 y porque se dan en el marco particular de la pacificación y el esfuerzo por construir una democracia antes inexistente en el país. Es este análisis, difícil de realizar por la ausencia de estudios previos y el desconocimiento de las peculiaridades de la cultura política salvadoreña, lo que constituye una tarea ineludible para entender el comportamiento electoral de marzo de 1994 y visualizar las tendencias futuras.

Este análisis debe ser multidimensional, combinando en los sectores sociales las características demográficas y económicas de sus integrantes, su ubicación en el territorio nacional, sus valores culturales, sus percepciones y aspiraciones, etc.

Aunque el objetivo de estas notas es explorar los procesos estructurales, conviene destacar algunos fenómenos coyunturales, pues orientan la investigación sobre aquellos.

En primer lugar, como era esperado, los resultados confirmaron al partido ARENA como la principal fuerza política del país en este momento, y como era previsible para unos y poco creíble 
para otros, el FMLN desplazó al Partido Demócrata Cristiano como la segunda. Por otra parte, y esto está relacionado con la apreciación siguiente, los nuevos partidos de corte religioso mostraron escaso potencial.

En segundo lugar, a pesar de la personalización manifiesta en los candidatos, principalmente para presidente de la república y alcalde de San Salvador, puede afirmarse que el voto para presidente, diputados y la Alcaldía de San Salvador fue un voto ideológico en el sentido que se votó por una opción política y no por personalidades (sucediendo lo contrario en la mayoría de los otros municipios). Esto marca una sustancial diferencia con elecciones realizadas en otros países donde candidatos independientes han logrado importantes triunfos. Quizás el mejor ejemplo lo brinde la elección de los candidatos a diputados, donde podemos afirmar que la mayoría de los electores no lograrían identificar a la mayoría de los que se beneficiaron con su voto.

Esto explicaría también, en parte, por que en la mayoría de municipios del país el tipo de candidatos del FMLN, seleccionados casi todos más por su trayectoria militante en las organizaciones del último que por su reconocimiento entre los habitantes de las localidades por cuales eran candidatos, hizo que la votación del FMLN en este nivel no correspondiera al nivel alcanzado a escala nacional.

¿Se modificará este rasgo a mediano plazo?

La respuesta dependerá, entre otras cuestiones, del nivel de consolidación del sistema de partidos políticos en el país.

En tercer lugar, y como se mencionara antes, el FMLN mostró su mayor fuerza no en las zonas ex-conflictivas, sino en el área metropolitana de San Salvador. Pero, ¿quiénes fueron los que votaron por la opción de izquierda además de su base militante?, ¿ise trata de jóvenes o población adulta?, ¿pertenecen mayoritariamente a los sectores populares o fue importante la votación de las clases medias a favor de esta organización?, ¿cómo se manifestaron electoralmente las mujeres?

Un amplio y vital campo de análisis se abre a partir de estas y otras interrogantes. 
Su conocimiento es además de fundamental importancia para la reestructuración del movimiento social y de la sociedad civil en general. Sin lo anterior, y por mucho que se afinen los procesos electorales y se desarrollen los partidos políticos, la construcción de la democracia en el país tendrá enormes limitaciones.

El reto para el FMLN, y en esto compartimos la opinión de uno de los ideólogos más claros de la derecha ${ }^{1}$, es lograr construir su nueva identidad, lo que implica definir sus opciones programáticas frente al desarrollo futuro del país.

Una tesis que hemos planteado en otro trabajo ${ }^{2}$ es útil mencionar al respecto: si la fortaleza del FMLN y del movimiento social durante los años de represión y guerra radicó en el alto nivel de organización alcanzado, éste se está convirtiendo en uno de los principales obstáculos para el desarrollo del primero como partido político de izquierda moderno y para la reestructuración del movimiento social en el momento actual.

Para el principal partido del país en el inicio del período político que se abrió en enero de 1992, ARENA, el reto fundamental, como lo reconocen muchos analistas, es la profundización de su modernización, proceso ininterrumpido desde su fundación aunque sea difícil reconocerlo aún para muchos. La tendencia más derechista no está definitivamente desplazada y la tendencia modernizante no ha alcanzado aún una hegemonía plena. Lo anterior depende en buena medida de la evolución del FMLN (en el sentido en que su debilitamiento disminuye la exigencia de esta modernización), y de la del tercer partido, que en el espectro político salvadoreño es indispensable considerar: el Partido Demócrata Cristiano.

Efectivamente, sería un profundo error desestimar las posibilidades de recomposición del PDC, muchos de cuyos votantes se inclinaron por ARENA ante la poca opción que representaba su candidato y sus divisiones internas (que reflejan también una crisis de identidad), sobre todo ante la incapacidad política que está mostrando el FMLN. No hay que olvidar las bases locales de poder que explicarían la permanencia política del Partido de Conciliación Nacional ( $\mathrm{PCN}$ ), a pesar de haber sido durante largo tiempo el partido oficial de las dictaduras militares. 
T a posibilidad de construcción de la democracia en El Salvador Uestá así vinculada, más que a los resultados electorales (aunque ellos son importantes para conocer la situación de los puntos de partida), a cuatro procesos: uno, la constitución de un sistema democrático de partidos políticos que logre recoger la diversidad social existente; dos, la reestructuración en profundidad del movimiento social y la sociedad civil; tres, la edificación de un Estado moderno, democrático y descentralizado; y cuatro, la superación del principal obstáculo a la construcción de la democracia en el país: la renovada concentración de la riqueza, que acentúa la pobreza y la exclusión social, y cuya mejor manifestación se puede observar en el sistema financiero.

Los resultados electorales indican que se abre un difícil período para lograr lo primero y lo tercero y tienden a reforzar la concentración de la riqueza en el país. Ellos no iluminan la oscuridad e incertidumbre que rodea al segundo.

Es en este momento que debemos alejarnos de la coyuntura y analizar históricamente las bases y los factores condicionantes de los resultados electorales.

Ante todo hay que recordar un hecho fundamental: la inexistencia, durante cincuenta años, de verdaderos partidos políticos de la clases dominantes. Este error cometido después de la insurrección popular de 1932, y que las hizo delegar el ejercicio del poder político directo en las fuerzas armadas (lo que constituye la clave de la militarización de la sociedad salvadoreña durante este largo período), casi le cuesta la pérdida de su poder económico a inicios de los años 80. Sin embargo podemos plantear hipotéticamente que la fundación del partido ARENA, aunque creado para defender sus intereses, no fue producto de su intervención directa en los primeros momentos, pero ocurre posteriormente una paulatina inserción de los elementos más claros políticamente de las clases dominantes en este partido y una continuada y aún no finalizada transformación del mismo en un moderno partido que responda a sus intereses de clase ${ }^{3}$.

¿Qué puede explicar esta capacidad de recomposición política? En nuestra opinión son claves dos rasgos de la burguesía salvado- 
reña: por un lado, el claro predominio de los sectores más importantes cuyos intereses económicos se encuentran en todas las esferas de la economía nacional (agricultura, industria, finanzas) ${ }^{4}$; por otro su extraordinaria modernidad empresarial generada por su preparación en el extranjero (especialmente en los Estados Unidos, y de allí posiblemente su interiorización de los valores del sistema político norteamericano donde los militares tienen un rol subordinado y el sistema político representativo un enorme vigor).

Al observar, aunque no se han hecho investigaciones exhaustivas al respecto, el funcionamiento de ARENA, se encuentra este sesgo empresarial y la cohesión alrededor de los grupos económicos más importantes.

A los factores anteriores habría que sumar el innegable sentido de pertenencia nacional de este sector social que se considera semejante a sus contrapartes internacionales (cuestión que no es ajena a la inexistencia de enclaves económicas extranjeros en el país a diferencia de otras naciones de Centroamérica y el Caribe), y uno de sus mayores motivos de orgullo radica en no haber abandonado el país y sus empresas en los años del conflicto.

Otro aspecto de gran importancia frente a la necesaria constitución de un sistema democrático de partidos políticos para avanzar en la construcción de la democracia en el país es la trayectoria del FMLN. Pensando y estructurado más como una organización que como un partido, este rasgo central en su constitución le impone limitaciones que hemos avanzado anteriormente.

¿Será posible la disolución de cinco organizaciones para convertirse en un partido único?

Creemos que nuevamente hay que recurrir a la historia para intentar responder a esta interrogante. Recordemos que el FMLN, a diferencia del Frente Sandinista de Liberación Nacional (FSLN), de Nicaragua, surge de la unión de cinco organizaciones que a pesar de la similitud de su planteamiento estratégico, se crean y crecen separadamente a lo largo de los años $70^{7}$, configurándose un sentido de pertenencia a determinada organización que nunca desapareció a pesar de haber luchado conjuntamente durante la década pasada. Lo anterior constituye un peso que no puede ser borrado por la simple voluntad. 
En este sentido, creemos que sólo la introducción de nuevos agrupamientos y miembros individualmente, en un proceso de real ampliación del FMLN, puede sentar las bases para su paulatina conversión en un partido de izquierda. Los mecanismos actuales de discusión y toma de decisiones por los dirigentes, y luego la consulta de éstas con las bases difícilmente puede conducir a esta transformación y más bien recuerda a procedimientos cuya validez democrática ha sido poco efectiva en muchos casos en otros países.

$Y$ si en los próximos años no logra constituirse, a partir del actual FMLN radicalmente transformado el partido de izquierda que la construcción de la democracia en El Salvador requiere, podemos afirmar que también será difícil que en los otros partidos políticos impongan su hegemonía las corrientes menos conservadoras. El tiempo político para este cambio es entonces extremadamente limitado y si el FMLN no logra efectuar esta transformación corre el riesgo, como muchos otros agrupamientos de la izquierda en América Latina, de convertirse en una minoría sin mayor trascendencia en el escenario político nacional.

Podemos decir, sintéticamente, que si durante las décadas anteriores la principal base de las clases dominantes estaba constituida por su capacidad empresarial, mientras que el principal activo de los sectores populares era su capacidad organizativa, las primeras han logrado convertir esta base en un partido político con muchos rasgos de modernidad (lo que no quiere decir necesariamente que exista o deba existir una democracia interna tal como la entiende la izquierda), mientras los segundos se enfrentan al reto de reconvertir la capacidad organizativa acumulada en el partido y la acción política que este período político exige.

Para ambos grandes agrupaciones, a pesar de las distintas intencionalidades, es indispensable promover una efectiva autonomía del movimiento social de las estructuras partidarias. Para el FMNL esto implica romper con una larga tradición de tutelaje bien intencionado. Para ARENA, evitar la tentación de crear sus apéndices en el movimiento social aprovechándose las transformaciones y reacomodos en curso. Los días previos a las elecciones de marzo de 1994 fueron testigos de la dificultad que tiene tanto el FMLN como muchas organizaciones del movimiento social para 
aceptar esta separación aunque su necesidad sea comprendida, y de los burdos intentos del partido ARENA para estructurar un movimiento social afin a sus posiciones políticas.

Sobre el movimiento social vinculado a los sectores populares queremos plantear, con fuerza y a pesar de que pueda suscitar incomodidades, que es indispensable su reestructuración a fondo. Que si bien tuvo la enorme virtud y capacidad de adecuarse a las condiciones de guerra imperantes en el país durante la década pasada, está totalmente desfasado respecto a los cambios operados en la economía, la sociedad y el Estado salvadoreños a partir de 1989, y respecto a los cambios económicos y políticos a nivel mundial. Y esta reestructuración debe ir más allá del cambio de dirigentes o de métodos de organización y lucha. Implica cuestionarse la vigencia y viabilidad de algunos movimientos sociales existentes y la construcción de otros realmente inexistentes (como el movimiento de mujeres o el ecologista que se limitan a organizaciones o grupos).

Sin transformar creativa y colectivamente esta capacidad organizativa acumulada lo anterior no será posible. Revisar la historia señala los posibles caminos y uno de los principales actores: así como una juventud visionaria construyó las organizaciones que terminaron constituyendo el FMLN durante la década de los 70, rompiendo con los esquemas predominantes en la izquierda por esos años, la juventud actual es clave en la reestructuración y el desarrollo que se necesita actualmente, especialmente por su enorme capacidad de romper con las visiones organizacionales que ya han caducado.

Para la construcción de la democracia en El Salvador era necesaria la constitución de un sistema democrático de partidos políticos y la reestructuración en profundidad no sólo del movimiento social que responde a los intereses de los sectores populares, sino en general de la sociedad civil, pues esta última no se limita a los primeros sino que incluye además las asociaciones vinculadas al desarrollo de los mercados ${ }^{5}$. En el caso salvadoreño se olvida a menudo que el alto nivel de restricciones y controles que imponen los grupos dominantes al funcionamiento de la libre competencia (y señalábamos el ejemplo del sector financiero), conforma uno de los que podríamos llamar "enclaves antidemocráticos" 6 , que cons- 
tituye uno de los mayores obstáculos para la construcción de la democracia en el país.

¿Se trata de una tarea imposible derivada de una visión utópica? No tenemos la respuesta pero si la claridad de que debe irse mucho más allá de lograr la autonomía del movimiento social existente de los partidos políticos, que es la casi exclusiva, aunque legítima existencia que postulan muchos dirigentes y sobre todo los integrantes del movimiento popular vinculado a los sectores populares.

Sólo lo anterior puede hacer posible contribuir a estructurar un sistema de partidos pluralista y moderno, construir un Estado democrático y romper con la renovada concentración de la riqueza que hoy se visualiza.

La investigación de los resultados electorales no debe limitarse entonces a su dimensión coyuntural, por dinámica y sugerente que sea. Las consecuencias de los resultados de eventos electorales como el de marzo y abril de 1994 en El Salvador son decisivos en la orientación del gobierno emergente y de las políticas que se impulsaran a partir de su administración. Pero su análisis, insistimos, exige trascender la coyuntura.

\section{Cuadro 1}

Resultados electorales a nivel nacional

(\% de los principales partidos)

\begin{tabular}{lccc}
\hline & 1984 & 1989 & $1994^{*}$ \\
\hline ARENA & 29.76 & 53.82 & 49.03 \\
PDC & 43.41 & 36.08 & 16.36 \\
FMLN/CD/MNR & - & - & 24.90 \\
\hline
\end{tabular}

PDC = Partido Demócrata Cristiano

$\mathrm{CD}=$ Convergencia Democrática

MNR = Movimiento Nacional Revolucionario

* $\quad$ : $\quad$ resultados de la primera vuelta. 


\section{Cuadro 2}

\section{Resultados electorales del municipio de San Salvador}

(\% de los principales partidos)

\begin{tabular}{lcccr}
\hline & 1985 & 1988 & 1991 & 1994 \\
\hline ARENA & 39.40 & 59.10 & 58.50 & 48.44 \\
PDC & 53.80 & 35.70 & 19.40 & 13.37 \\
CD & - & - & 14.50 & 3.08 \\
FMLN & - & - & - & 24.48 \\
\hline
\end{tabular}

\section{Notas:}

1. Expresada en el editorial de La Prensa Gráfica, 20 de mayo de 1994, San Salvador.

2. Trabajo en que hemos intentado analizar el peso de los distintos obstáculos que enfrenta este proceso. Ver: "Los obstáculos a la democratización en El Salvador", Mario Lungo, en El Salvador en Construcción \# 11, agosto 1993, San Salvador.

3. Planteamos ya a finales de los años 80 que era necesario reconocer el dinámico proceso de recomposición política de las clases dominantes, expresada en la transformación sufrida por el partido ARENA. Ver: El Salvador durante los 80: contrainsurgencia y revolución, capítulo 4, Mario Lungo, EDUCA/FLACSO, San José, 1990.

4. Existen al respecto opiniones divergentes. Ver, entre otros: Wim Pelupessy: "El sector agroexportador de El Salvador: la base económica de una oligarquía no fraccionada", en Boletín de Estudios Latinoamericanos y del Caribe \# 43, 1987, CEDLA, Amsterdam; y Jeffery Paige: "Coffee and Power in El Salvador", en Latin América Research Reoiew, vol. 28, number 3, 1993, University of New Mexico. Respecto al último nos parece que la división entre una fracción agro-financiera y otra agro-industrial tiene poca base en el momento actual.

5. En un trabajo reciente se postula que para el éxito de las transiciones democráticas, entendidas como el establecimiento de las reglas básicas de un régimen político democrático, y su consolidación, entendidas como las espectativas generalizadas en la sociedad de que estas reglas se van a cumplir, es clave la existencia previa de una sociedad civil desarrollada. Aunque no compartimos otras ideas de este trabajo, la anterior es sugerente para el estudio del caso salvadoreño. Ver: La primacia de la sociedad civil. El proceso de formación de la España democrática, Víctor Pérez Díaz, ALIANZA Editorial, Madrid, 1993.

6. Hemos utilizado la idea de "enclave antidemocrático" del trabajo de Manuel Antonio Garretón y Malva Espinoza: " 2 Reforma del Estado o cambio en la matriz socio-política?", publicada en Perfiles Latinoamericanos \#1, diciembre de 1992, FLACSO, México, donde los autores desarrollan la idea de la persistencia de "enclaves autoritarios" en el proceso de transición chileno.

7. Ver: El Salvador en los 80: contrainsurgencia y revolución, capítulo 5. 